DOI 10.37882/2223-2982.2020.11.15

\title{
ИНДИВИДУАЛЬНЫЕ ОБРАЗОВАТЕЛЬНЫЕ ТРАЕКТОРИИ: НОВАЯ РЕАЛЬНОСТЬ ВЫСШЕГО ПРОФЕССИОНАЛЬНОГО ОБРАЗОВАНИЯ В РОССИИ
}

\section{INDIVIDUAL EDUCATIONAL TRAJECTORIES: THE NEW REALITY OF HIGHER PROFESSIONAL EDUCATION IN RUSSIA \\ S. Ignatov \\ E. Mulyavina}

Summary: The aim of the research is to study the possibilities of actualizing the format «individual educational trajectory» in the system of professional training of university students. The article discusses the problems of developing its content basis. The authors consider approaches to its modeling, offer one of the possible options for structuring the variable component of this format.

Keywords: individual educational trajectory, professional training of university students.

\author{
Игнатов Сергей Борисович \\ К.н., дочент, Тюменский индустриальный университет \\ ignatoff.se2017@yandex.ru; \\ Мулявина Элеонора Александровна \\ к.н., дочент, Тюменский государственный \\ институт культуры \\ emulyavina@ramdler.ru
}

Аннотация: Целью исследования является изучение возможностей актуализации формата «индивидуальная образовательная траектория» в системе профессиональной подготовки студентов вуза. В статье обсуждаются проблемы разработки его содержательной основы. Авторы рассматривают подходы к её моделированию, предлагают один из возможных вариантов структурирования вариативной составляющей этого формата.

Ключевые слова: индивидуальная образовательная траектория, профессиональная подготовка студентов вуза.
4 еловечество входит в новый постиндустриальный мир, который характеризуют ускоряющаяся темпоральность, грандиозное увеличение цивилизационных показателей, гиперэкспоненциальный рост объёма научных знаний, быстрая смена образцов техники и технологий, стремительная цифровизация и информатизация, которые вызывают колоссальные преобразования во всех сферах жизни общества, структуре занятости населения и спектре профессий.

Чтобы быть успешным в этом мире человеку необходимо строить жизнь и профессиональную деятельность по новым лекалам. Особую роль в их освоении играет система высшего профессионального образования как завершающая ступень формального обучения для значительной массы граждан. Его стратегической целью становится подготовка специалистов новой формации, готовых к:

- строительству оптимальных жизненных, профессиональных и образовательных стратегий в динамично изменяющемся мире, продуктивной профессиональной деятельности;

- мобильности в профессиональном самоопределении на протяжении всей жизни, быстрому «переучиванию» и расширению поля своих возможностей, а при необходимости и к оперативной смене профиля своей деятельности;

- пониманию трудностей перехода в смежные об- ласти или за их пределы, обретению новых профессиональных и метапредметных компетенций, активному освоению новых функций, для решения междисциплинарных задач и осуществлению идей устойчивого развития общества;

- работе в команде, поиску в кризисных ситуациях правильных и быстрых нестандартных решений и их эффективному использованию;

- освоению навыков прогнозировать, «заглядывать за горизонт» событий, генерировать новые идеи, ставить цели, планировать, разрабатывать и прокладывать оптимальный маршрут к их достижению, учитывая при этом потребности общества в специалистах новых профилей, свои индивидуальные способности и потенциальные возможности в их освоении.

Формирование выпускников с набором таких качеств требует концептуальных перемен в системе их подготовки и вывода учебного процесса за рамки сложившейся традиционной системы. Наряду с фундаментальной узкопрофессиональной подготовкой необходимо обеспечить им условия для освоения широкого междисциплинарного поля и создать возможности для реализации собственного пути к постижению профессии $[4,5,7]$.

В последние десятилетия науки об образовании всё 
чаще обращаются к поискам способов трансформации вузов, созданию новых образцов их функционирования, разработке содержания образования и технологий обучения, способных повысить коэффициент полезного действия высшей школы в «производстве» специалистов, востребованных не только на актуальном рынке труда, но и в обозримом будущем. По мнению ряда исследователей в области теории и методики профессионального образования одним из перспективных в этом плане может стать формат (или модель) подготовки выпускника, получивший название «индивидуальная образовательная траектория» (ИОТ) [1, 3].

Достаточно широкое распространение эта модель нашла в странах Западной Европы и Америки. На обучение с использованием её инструментов перешёл ряд вузов стран ближнего зарубежья (Казахстан, Белоруссия и др.). Она становится новой реальностью высшего профессионального образования и в России [6].

О своём переходе на эту модель обучения заявили отдельные трансформирующиеся вузы (Т-вузы) Москвы, Санкт-Петербурга, Урала и Сибири. На сегодняшний день разработаны концептуальные подходы к организации процесса обучения студентов в идеологии ИОТ, обозначены основные этапы её освоения, обсуждаются образовательные технологии, адекватные этому формату, система тьюторского сопровождения обучающихся. В рамках пилотных проектов осуществляются психолого-педагогические исследования динамики личностных качеств студентов, обучающихся по индивидуальным траекториям, накоплен значительный объём эмпирических данных.

Однако опыт использования модели ИОТ в разнопрофильных Т-вузах ставит множество вопросов в плане недостаточности теоретико-методологического и методического обеспечения, что существенно снижает шансы её внедрения в повсеместную практику.

Одной из малоизученных проблем организации ИОТ в вузе является моделирование пространства образовательных возможностей (ПОВ) студентов. Оно включает содержание образования, совокупность технологических, организационных и технических средств, помогающих студенту выстроить и реализовать собственный путь его освоения и продвижения к профессии. На каждом этапе следования студента по этому пути ПОВ (особенно в его содержательной части) будет изменяться, корректироваться, а возможно и кардинально перестраиваться.

Ориентиры для его моделирования задаёт стратегическая цель обновляющегося высшего образования. Соподчинённые с ней учебные и воспитательные цели направлены на развитие у выпускника тех профессио- нальных и личностных качеств, которые будут ему необходимы для успешного освоения профессии в формате ИОТ:

- способности к самоопределению, самоорганизации, саморегуляции, проектированию своей деятельности, оперативному, тактическому, перспективному и стратегическому её планированию, рефлексии и самокоррекции;

- концептуального мышления, умения прогнозировать желаемое будущее, ориентируясь на перспективы развития общества, изменения в сфере занятости, спектре профессий и в соответствии с этим выбора стратегии освоения ИОТ;

- компетенций, предусмотренных ФГОС ВО, с учётом их значимости в организации личной жизни и производственной деятельности в обозримом будущем;

- умения просчитывать последствия своих действий, понимания своей социальной миссии и значимости своей профессиональной деятельности в обеспечении устойчивого развития общества;

- мобильности и готовности к решению междисциплинарных задач и командной работе в смежных областях и за их пределами.

Ключевой составляющей ПОВ, обеспечивающей успешность их формирования, является содержание образования. Однако вопросы его моделирования в контексте ИОТ изучены недостаточно. Пока не выработаны общие критерии разработки его структуры, остаются открытыми вопросы, касающиеся принципов конструирования и наполнения её информационного поля. [2].

Основная сложность в решении этих вопросов связана с колоссальным спектром направлений и профилей подготовки выпускников. В реестр Минобрнауки включено 58 укрупнённых групп направлений (УГН) подготовки бакалавров, внутри каждой из которых выделяется около десятка более узких направлений. В каждом направлении выделяются отдельные профили, количество которых может быть весьма значительным. Поэтому на стартовой ступени разработки ПОВ можно обозначить лишь контуры его содержательной основы, которую определяет учебный план профиля.

Каждый вуз, создавая учебные планы для выбранных им направлений и профилей подготовки выпускников, ориентируется на основную образовательную программу (ООП, разработанную на основе примерной основной образовательной программы (ПООП), с учётом ФГОС, рекомендаций консорциума «родственных» вузов и рынка труда.

Его базис составляют дисциплины, входящие в первую часть учебных планов (ранее называвшуюся ин- 
вариантной), которая включает регламентированный перечень социально-гуманитарно-экономических, естественнонаучных и профессиональных дисциплин, обязательных для изучения и перечень компетенций, формируемых у студента. Благодаря чёткой регламентации дисциплин в этой части снижается (либо вообще исключается) сложность перехода студента с одного профиля на другой внутри данного направления подготовки не только в конкретном вузе, но и при переводе в другой «родственный» ВУЗ.

В сложившемся традиционном высшем образовании естественнонаучные и социально-гуманитарные дисциплины, закладывающие элементы концептуального мышления, расширяющие общекультурный кругозор начинающего студента, формирующие его метапредметные, универсальные, общепрофессиональные и культурные компетенции, изучаются на первом и втором курсах. При обучении в формате ИОТ студент может их осваивать на разных её этапах. Но при этом необходимо учесть, что будет меняться характер содержания дисциплин и способы их освоения. Если на младших курсах они носят пропедевтический ознакомительный характер, то на старших - обобщающий, завершающий формирование целостной картины мира и концептуального мышления выпускника.

При организации ИОТ в учебных планах, как и в случае традиционной системы подготовки, устанавливается определённая последовательность изучениядисциплин, составляющих основу будущей профессии. И «перескочить» через её барьер весьма затруднительно, а иногда и практически неосуществимо. Например, в технических вузах невозможно начать изучение таких дисциплин, как «сопротивление материалов» или «электротехника», не освоив курсы высшей математики и физики. В биолого-медицинских - начать изучать генетику, не изучив биохимию. В языковом вузе, прежде чем освоить курс «общего языкознания», необходимо изучить введение в языкознание, фонетику, лексику, морфологию, синтаксис и другие частные языковые дисциплины. Основательно освоить профессиональные юридические дисциплины невозможно без знания основ римского права. И перечень подобных примеров можно продолжить.

Горизонтальное расширение содержательного поля ПОВ и его углубление в рамках этой части учебных планов осуществляется, как правило, за счёт усиления междисциплинарных связей, интеграции разнопредметных знаний, реализации принципа трансдисциплинарности, обновления информационного поля учебных дисциплин с учётом новейших достижений в науках о природе, обществе, человеке, в технике и технологиях.

Вторая часть учебных планов (ранее называвшаяся вариативной) имеет неисчерпаемые потенциальные возможности в расширении индивидуального ПОВ студента. Именно её многовекторное содержательное поле создаёт ему реальную возможность самостоятельно выстраивать собственную ИОТ на основе выбора тематики предлагаемых для изучения курсов и темпоральности их освоения.

Но именно с её формированием связаны самые серьёзнейшие проблемы и наибольшие трудности. При том обилии УГН, которое представлено в реестре Минобрнауки, привести контуры ПОВ к какому-то общему знаменателю и унифицировать содержание второй части учебных планов весьма затруднительно. Но обосновать общие принципы её построения возможно, в рамках определённой УГН решение этой проблемы вполне реально. Весьма своевременной является рекомендация Минобрнауки начинать профилизацию (ранее называлась специализацией) с третьего курса, когда студент уже освоил систему общеобразовательных дисциплин. Это позволит сохранить полноценность общеобразовательного уровня всех направлений в рамках конкретных УГН и в то же время отразить их специфику.

Отдельные Т- вузы, создавая эту часть ПОВ, ориентируются на одну из моделей, разработанных ещё в девяностые годы прошлого века в зарубежной школе [8].

Эта модель включает четыре взаимодополняющие части:

- ядерный курс (the Core Curriculum),

- меж- и внутрипредметную (the Curriculum of Connections),

- практическую (the Curriculum of Practice),

- идентификационную (the Curriculum of Identity).

Ядерный курс рассматривается как стартовая площадка обучения и включает ключевые факты, понятия, принципы и умения, существенные для изучения последующих дисциплин.

Вторая часть включает элективы и создаётся для того, чтобы обучающиеся имели возможность применять приобретенные знания в ситуациях необходимости меж- и внутрипредметного синтеза.

Третья часть предполагает формирование аналитических, исследовательских умений.

Четвертая часть предоставляет возможность раскрывать индивидуальность в процессе учебной, главным образом самостоятельной, работы.

Однако, при практической реализации этой модели в вузах, возникает ряд проблем. При её формировании из рекомендуемого консорциумом перечня дисциплин вузом выбираются наиболее соответствующие его тради- 
циям, профильной направленности ООП, потребностям регионального рынка труда и запросам потенциальных работодателей. Этот список дополняется разработанными преподавателями вуза курсами, вариативными модулями, спецкурсами, элективами, факультативами и другими структурными элементами.

Наборы включённых в неё дисциплин и курсов и их содержание для одного и того же профиля в разных вузах могут существенно различаться. Это вызывает определённые трудности для студента при переводе в другой вуз. И даже переход между близкими профилями внутри одного вуза вызывает затруднения, связанные с несоответствием наборов формируемых компетенций, взаимозаменяемостью и взаимозачётностью избираемых для изучения курсов и их контента.

Студентам предлагается избыточный перечень подобных структурных элементов, дополняющих содержание базовых дисциплин и расширяющих их кругозор. Но, как показывает практика, зачастую подбор этих курсов носит «стихийный» характер, их информационное поле бывает недостаточно глубоко связано с содержательными линиями дисциплин первой части учебных планов, отражает в основном научные интересы и приоритеты отдельных преподавателей [2].

Как не растеряться студенту и не запутаться в необозримом поле предлагаемых курсов и не потерять стратегическую линию восхождения к профессии? Конечно, в этом плане велика роль института тьюторства. Тьютор выступает, и помощником студента, и советчиком, и его «путеводителем» по ИОТ. При этом выбор студентом того или иного курса будет лишь отчасти самостоятельным.

Для обеспечения возможности самостоятельного выбора вариативных элементов ООП необходима их систематизация и создание обязательных пулов дисциплин по выбору, продуманной с точки зрения компетентностной «равноценности». Важно позаботиться о взаимозаменяемости, встроенных в них курсов и возможной их взаимозачётности при переходе с одного профиля обучения на другой или из одного вуза в другой. Количество пулов должно быть регламентировано и утверждено на уровне консорциума вузов, близких по направлению. Студент имеет право выбора одной из дисциплин пула. При этом зачёт по выбранной дисциплине означает и зачёт всего пула. Однако разработка системы таких пулов и входящих в них равнозначных курсов по выбору - одна из сложнейших методических задач. Трудности вызывает не только создание контента курсов по выбору, но и определение их равнозначности и «веса» в подготовке специалиста.

Решение этих проблем требует серьёзных научнометодических исследований команд преподавателей вузов по изучению междисциплинарных связей базовых дисциплин первой части учебного плана, выявлению лакун в их содержании, выработке рекомендаций по их заполнению за счёт дисциплин вариативной части. В этом плане будет полезной работа по созданию матрицы образовательных ресурсов и конструирования иерархии взаимозаменяемых курсов.

\section{ЛИТЕРАТУРА}

1. Вергун, Т.В., Колосова, 0.Ю., Гончаров, В.Н. Индивидуальные образовательные траектории студентов в высшей школе: к постановке проблемы // Современные наукоёмкие технологии. - 2016. № 12 - 2. - С. $313-317$.

2. Гамукин В.В. Индивидуальные образовательные маршруты в вузе // Инженерное образование. - 2019. № 25. - С 27 - 36

3. Зеер, Э.Ф., Сыманюк, Э.Э. Индивидуальные образовательные траектории в системе непрерывного образования // Педагогическое образование в России. - 2014. № 3. - С. $74-82$.

4. Зинченко, Ю.П., Дорожкин, Е.М., Зеер Э.Ф. Психолого-педагогические основания прогнозирования будущего профессионального образования: векторы развития // Образование и наука. - 2020. № 22(3). - С. 11 - 35.

5. Лукша, П., Кубиста. Д., Ласло, А., Попович, М., Ниненко, И. Образование для сложного общества. Доклад Global Education Futures / П. Лукша, Д. Кубиста, А. Ласло и др. Москва: Российский учебник, 2018. - С. 213.

6. Мясоедова, В.А., Лебедева, Н.А. Проблемы модификации деятельности российских вузов на основе мировой практики развития образовательных учреждений // Современное образование. - 2016. № 4. - С. 29 - 37.

7. Новиков, А.М. Постиндустриальное образование. Москва: Эгвес. - 2008. - 136 с.

8. Tomlinson C.A. The Parallel Curriculum / C.A. Tomlinson, S.N. Kaplan, J.S. Renzulli et al.: Corwin Press, 2002. - 270 p.

( ) Игнатов Сергей Борисович (ignatoff.se2017@yandex.ru), Мулявина Элеонора Александровна (emulyavina@ramdler.ru) Журнал «Современная наука: актуальные проблемы теории и практики» 